ORIGINAL ARTICLE

\title{
The association between psychosocial characteristics at work and problem drinking: a cross-sectional study of men in three Eastern European urban populations
}

\author{
M Bobak, H Pikhart, R Kubinova, S Malyutina, A Pajak, H Sebakova, R Topor-Madry, Y Nikitin, \\ W Caan, M Marmot
}

Occup Environ Med 2005;62:546-550. doi: 10.1136/oem.2004.017202

See end of article for authors' affiliations

Correspondence to

Dr M Bobak, Department of Epidemiology and

Public Health, University

College London, 1-19

Torrington Place, London

WC1E 6BT, UK;

m.bobak@ucl.ac.uk

Accepted 4 March 2005

\begin{abstract}
Background: Psychosocial factors at work are thought to influence health partly through health behaviours.

Aims: To examine the association between effort-reward imbalance and job control and several alcohol related measures in three eastern European populations.

Methods: A cross-sectional study was conducted in Novosibirsk (Russia), Krakow (Poland), and Karvina (Czech Republic). The participants completed a questionnaire that included effort-reward at work, job control, and a number of sociodemographic variables. Annual alcohol intake, annual number of drinking sessions, the mean dose of alcohol per drinking session, and binge drinking $(\geqslant 80 \mathrm{~g}$ of ethanol in one session at least once a week) were based on graduated frequencies in the questionnaire. Data were also available on problem drinking ( $\geqslant 2$ positive answers on CAGE questionnaire) and negative social consequences of drinking. All male participants in full employment $(n=694)$ were included in the present analyses.

Results: After controlling for age and centre, all indices of alcohol consumption and problem drinking were associated with the effort-reward ratio. Adjustment for material deprivation did not change the results but adjustment for depressive symptoms reduced the estimated effects. Job control was not associated with any of the alcohol related outcomes.

Conclusions: The imbalance of effort-reward at work is associated with increased alcohol intake and problem drinking. The association appears to be partly mediated by depressive symptoms, which might be either an antecedent or a consequence of men's drinking behaviour.
\end{abstract}

$\mathrm{T}$ he association between the psychosocial environment at work and cardiovascular diseases or other health outcomes has attracted considerable attention. ${ }^{1-6}$ Most studies used the job strain model developed by Karasek and Theorell based on the combination of decision latitude (job control) and psychological work demands; ${ }^{27}$ social support was added later as additional dimension. ${ }^{8}$ More recently, Siegrist's model based on the imbalance between effort and reward at work has also been shown to predict health independently from job strain variables. ${ }^{10}$

The literature on the relation between psychosocial factors at work and health behaviours, such as smoking or drinking, is less consistent. With respect to alcohol, most studies found that an unfavourable psychosocial work environment is associated with higher levels of alcohol consumption, ${ }^{11}{ }^{12}$ alcohol dependence, ${ }^{13-15}$ or alcohol related problems, ${ }^{16}$ but some investigators found no relation. ${ }^{17}$ Most published studies used the job strain model; only one study to our knowledge investigated the relation between effort-reward imbalance and alcohol intake. ${ }^{15}$ Exploring the effort-reward model may be critical, because a consistent and persistent effect of alcohol use is to shift the perceived balance of anticipated reward versus punishment (that is, physical or emotional distress). In other words, alcohol can change "the way people weigh up the costs and benefits in a conflict situation where they feel torn between different courses of action" ${ }^{18}$

In this study, we investigated the association between effort-reward and alcohol in Central and Eastern Europe. Alcohol is a major cause of ill health in the region, ${ }^{19} 20$ possibly because of the binge drinking pattern common in parts of the region..$^{21}$ Problem drinkers may even affect the health of their compatriots, for example the victims of violence associated with alcohol..$^{22}$ Psychosocial factors at work have previously been found to be associated with myocardial infarction, ${ }^{23}{ }^{24}$ poor self-rated health, ${ }^{25}$ and depressive symptoms ${ }^{26}$ in several countries of the region. We used cross-sectional data from population samples in three countries to examine the possible role of effort-reward imbalance in the levels and patterns of drinking and the negative consequences of drinking.

\section{METHODS}

\section{Study populations}

The data come from the pilot HAPIEE Study (Health, Alcohol and Psychosocial factors In Eastern Europe), a cross-sectional study in urban population samples in Novosibirsk (Russia), Krakow (Poland), and the twin city Karvina-Havirov (Czech Republic) conducted in 1999-2000. Subjects in the age group 45-64 were randomly selected from population registers. In Poland and the Czech Republic, data were collected during home interviews (after sending an explanatory letter inviting the subjects to participate in the study), and in a short examination in a clinic. In Russia, all participants were interviewed in a clinic. Response rates ranged from $65 \%$ in Poland to $71 \%$ in the Czech Republic. Because the low levels of alcohol intake and the lower age of retirement in women reduce both the numbers of women with valid data and the statistical power, the analyses were restricted to men who were in full-time employment in the last 12 months before 
Main messages

- The imbalance between effort and reward at work is associated with increased levels of alcohol consumption and problem drinking.

- The association is related to depression symptoms which may be either an antecedent or a consequence of men's drinking behaviour.

- Low control at work was not associated with alcohol and drinking indices.

the survey. The study was approved by ethical committees in the UK and all three countries, and all participants gave written consent.

\section{Measures of alcohol consumption and problem drinking}

Participants completed a structured questionnaire with extensive data on participants' medical history, socioeconomic status, psychosocial factors, and diet. Alcohol consumption was measured by the graduated frequency (GF) method: how often during the past 12 months did the subjects drink more than $X$ amount of alcohol. In terms of alcohol amounts per occasion, there were six mutually exclusive categories (expressed in local units of beer, wine, and spirits) corresponding to the following amounts of ethanol: >180 g; 140-179 g; 100-139 g; 60-99 g; 20-59 g; and $<20$ g. There were nine mutually exclusive categories of frequency, ranging from "never" to "daily/almost daily". Details are available on request; additional measurements were described elsewhere. ${ }^{21}$

From the graduated frequency responses, for each participant we calculated the number of drinking occasions in the last year, the average dose per occasion, the annual alcohol intake, and whether the subject was a binge drinker (at least $80 \mathrm{~g}$ of ethanol per drinking session at least once a week). Internal consistency and reliability of the responses was assessed by cross-tabulations and correlations of different measures, and by repeating the measurements in a subsample of responders after six months; among working men $(\mathrm{n}=101)$, the Spearman correlation coefficient was 0.69 for drinking frequency (on 9-point scale) and 0.81 for annual alcohol intake. In Russia, in addition, serum GGT was measured in a sub-sample of subjects; the alcohol intake measures correlated strongly with serum GGT. ${ }^{27}$

In addition to alcohol intake, we also assessed the presence of alcohol related problems, firstly using the CAGE questionnaire, ${ }^{28}$ covering the preceding 12 months, and secondly by a questionnaire on drinking related problems concerning everyday life, adapted from items which have been used in North America ${ }^{29}{ }^{30}$ and western Europe. ${ }^{31}$ The latter questionnaire contained questions on problems due to alcohol with friends, family, work, police, etc. For both questionnaires, two or more positive answers were taken as problematic. The Cronbach's alpha coefficient of internal consistency was more than 0.7 for both questionnaires in each country; in the repeated sample, $94 \%$ of men were classified in the same category of problem drinking $(\geqslant 2$ positive answers to CAGE questionnaire).

\section{Psychosocial characteristics at work}

We used the standard questionnaire on effort (6 questions) and reward (11 questions). ${ }^{32}{ }^{33}$ Average scores were calculated if a minimum of 5 out of 6 questions on effort and 9 out of 11 questions on reward had valid answers. The Cronbach's alpha was 0.68 for extrinsic effort questions and 0.75 for
Policy implications

- When identifying determinants of problem drinking in population, psychosocial work environment should be also considered.

- The benefits of improving the balance between effort and reward at work may also include reduction in harmful drinking behaviour.

reward questions. The logarithmically transformed ratio of effort to reward was used as a continuous measure (the ratio of the respective scores) in order to improve the statistical power of this instrument. ${ }^{25} \mathrm{Job}$ control was assessed by six questions ("Do you have the possibility of learning new things through your work?", "Does your work demand a high level of skill or expertise?", "Does your job require you to take the initiative?", "Do you have a choice in deciding how you do your work?", "Do you have a choice in deciding what you do at work?", "Do you have a good deal of say in decisions about work?"), and a score was calculated using answers to these six questions. Since the questionnaire included only one question on job demand, we present results for effortreward and job control only.

\section{Covariates}

Several social characteristics were used as covariates. Education was categorised into four categories: primary or less, vocational (apprenticeship), secondary (A-level equivalent), and university degree. Material deprivation was assessed by three questions about how often the subject's household had difficulties to buy enough food or clothes and to pay bills for housing, heating and electricity. The possible answers were "never or almost never", "sometimes", "often", and "always". These responses were coded as 0,1 , 2 , or 3, and a deprivation score was calculated as their sum. We also assessed the presence of depressive symptoms using the CES-D scale (Center for Epidemiologic Studies Depression Scale) consisting of 20 items. ${ }^{34}$ The total score ranges between 0 and 60; the full scale was used in the analysis as a continuous variable.

\section{Statistical analysis}

As mentioned above, only men with employment were included in the analyses. The variables of interest were first cross-tabulated and inspected. The outcome variables included the following binary variables: binge drinking, problem drinking (two or more positive answers to CAGE questionnaire), two or more negative consequences of drinking, and being in the highest tertile of annual alcohol intake, mean dose of alcohol per drinking session, and number of drinking sessions in the last year. (The latter three variables were dichotomised because their distribution was severely skewed.) The association between the outcomes and the logarithm of the effort-reward ratio and the job control score were analysed by logistic regression. Firstly, we estimated odds ratios adjusted for age and centre. The effects are expressed per 1 standard deviation increase in effortreward ratio and job control score. The age adjusted estimates were similar in each centre (for all outcomes, p values for heterogeneity between centres were $>0.2$ ), and data were therefore pooled and we controlled for centre in the analyses. Secondly, we additionally adjusted for material deprivation and education as potential confounders. Finally, since depressive symptoms are associated with alcohol and could serve as either confounding or mediator of the job-alcohol relation, we further adjusted for the depression score. 
The study was approved by ethical committees in each participating country and at University College London.

\section{RESULTS}

Descriptive characteristics of the 694 men included in the analyses are shown in table 1 . The mean annual consumption of alcohol and the mean annual number of drinking sessions was highest in the Czech Republic, while the mean dose of alcohol per drinking session and the frequency of binge drinkers, problem drinkers, and men who experienced negative consequences of drinking were highest in Russia. The proportion of men with effort higher than reward was highest in the Czech Republic and lowest in Poland. Levels of deprivation and depression score were highest in Russia.

Results of the analyses are shown in table 2. After controlling for age and centre, effort-reward ratio was associated with binge drinking, problem drinking, and negative consequences of alcohol (borderline significance). Further adjustment for deprivation and education had little effect but controlling for depression score approximately halved the estimates, and only the relation with problem drinking remained statistically significant. Job control was positively associated with all problem drinking indices, but none of the associations reached statistical significance.

After controlling for age and centre, a high annual intake, the typical dose per drinking session, and a high number of drinking sessions were positively and significantly associated with effort-reward ratio (table 2 ). Controlling for deprivation and education reduced the estimate for high mean dose per session but not for high annual intake and number of drinking sessions. Additional adjustment for depression reduced the estimates, but high annual intake and number of drinking sessions retained statistical significance. Job control was not associated with annual intake, mean dose per occasion, or the annual number of drinking sessions.

We also examined separate effects of effort and reward. We found that reward was not associated with any of the drinking related outcomes; virtually all the effects were due to the relation between drinking and effort (not shown in table).

\section{DISCUSSION}

In these population based data from central and eastern Europe, we found that all indicators of alcohol intake and problematic drinking were associated with effort-reward imbalance but not with job control. The association with effort-reward imbalance was independent of deprivation and education but some of it was related to depressive symptoms.

Alcohol accounts for a substantial burden of ill health in the region, especially in the former Soviet Union. ${ }^{20}{ }^{35}$ The social and health impact of alcohol in the region is at least partly related to the pattern of binge drinking. ${ }^{2136}$ It is therefore important to understand the distribution of drinking and alcohol related problems in the population. Alcohol intake has previously been found to be associated with education and marital status in Russia $^{37}$ and with education in the Czech Republic ${ }^{38}$ and Poland (unpublished data). Psychosocial factors are often thought to be at least partly responsible for the association between socioeconomic position and health behaviours. ${ }^{39}$ The finding of an association between effort-reward ratio and most indices of problem drinking alcohol consumption is therefore plausible.

Our results are consistent with a recent report from the British civil servants study in which alcohol dependency in men was associated with effort-reward imbalance but not with job control. ${ }^{15}$ However, several other studies, both crosssectional and prospective, found that job strain or other measures of stressful work conditions was also associated with alcohol and alcohol related problems. ${ }^{11-14} 1640$ It is possible that work characteristics and their relation with life style factors are relatively specific for each study population, and this may account for the differences between studies. For example, a specific change to longer hours of work can lead to higher alcohol consumption; ${ }^{41}$ the trade union Unison suggests that group effects within the work "environment" can lead to "excessive" drinking after stress. ${ }^{42}$ Interestingly, the association between effort-reward imbalance and drinking indicators were only due to the relation with effort, but not reward.

The age and centre adjusted associations between effortreward imbalance and drinking were moderately strong. The odds ratios around 1.4 per 1 standard deviation suggest that men separated by 2 standard deviations (roughly corresponding to comparing the top and bottom sixths of the population distribution) would have approximately double odds of binge and problem drinking and negative social consequences of drinking.

The association between work characteristics and alcohol related problems was substantially attenuated after controlling for depression score, which suggests that a major part of the association is related to depressive symptoms. The crosssectional nature of the data does not allow identification of the chain of causation. The problem is less worrying with the work characteristics, since prospective cohort studies found that job control and effort-reward imbalance precede both alcohol problems ${ }^{13-15}$ and depression. ${ }^{43}{ }^{44}$ However, the relation between depressive symptoms and alcohol is more complex, and may be influenced by age, gender, and culture. ${ }^{18}$ It is possible that drinking problems could precede depression, could develop in parallel with depression, or could be a consequence of depression. Since a whole range of scores for depressive symptoms was used in this study (including many cases with sub-clinical scores), it is

Table 1 Characteristics of the men included in the analyses

\begin{tabular}{|c|c|c|c|c|}
\hline & $\begin{array}{l}\text { Czech Rep. } \\
(n=174)\end{array}$ & $\begin{array}{l}\text { Russia } \\
(\mathrm{n}=364)\end{array}$ & $\begin{array}{l}\text { Poland } \\
(n=156)\end{array}$ & $\begin{array}{l}\text { Total } \\
(n=694)\end{array}$ \\
\hline Mean annual consumption of ethanol $(\mathrm{g})$ & 8603 & 5281 & 4886 & 6018 \\
\hline Mean number of drinking session per year & 184.0 & 75.3 & 95.2 & 106.7 \\
\hline Mean dose per drinking session (g of ethanol) & 43.7 & 64.1 & 41.6 & 54.1 \\
\hline Binge drinking ( $>80 \mathrm{~g}$ ethanol at least once a week) (\%) & 5.2 & 11.8 & 4.5 & 8.5 \\
\hline Problem drinking (CAGE $2+)(\%)$ & 20.4 & 37.6 & 13.9 & 27.5 \\
\hline Social consequences of drinking (\%) & 10.0 & 18.9 & 8.6 & 14.2 \\
\hline Mean age (years) & 52.1 & 52.8 & 53.6 & 52.8 \\
\hline Mean deprivation score (0-9) & 1.6 & 2.6 & 1.4 & 2.1 \\
\hline Mean depression score (0-60) & 9.4 & 11.5 & 9.3 & 10.5 \\
\hline Primary education only (\%) & 5.8 & 9.9 & 2.6 & 7.2 \\
\hline Married (\%) & 87.4 & 89.9 & 83.2 & 87.8 \\
\hline Effort-reward ratio $>1(\%)$ & 12.1 & 7.1 & 4.5 & 7.8 \\
\hline
\end{tabular}




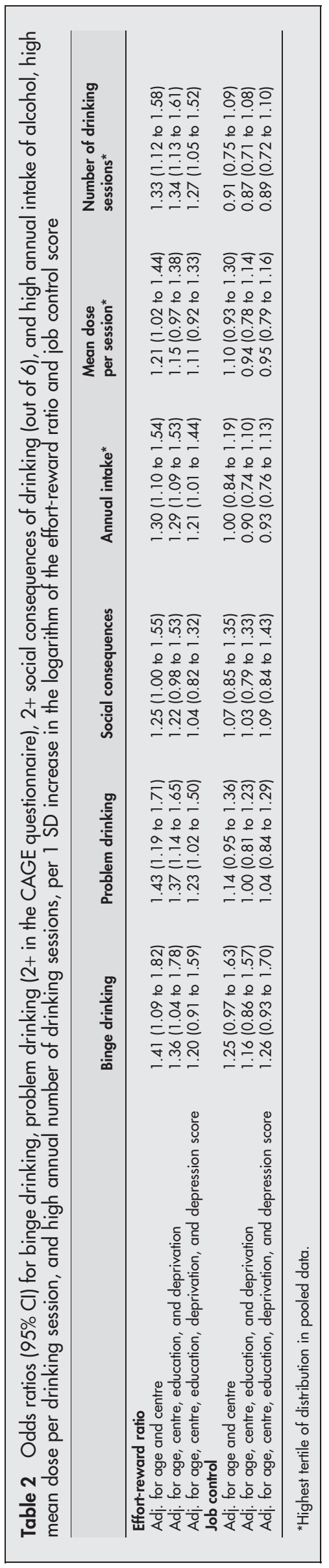

important to consider that common features of alcohol disorders (for example, expressed as guilt, helplessness, or insomnia) would also rate as isolated symptoms of "depression". The World Health Organisation notes that depression often co-occurs with alcohol misuse and it mentions the possibility that a depressed person "may have been using alcohol to self-medicate" ${ }^{45}$ However, experience at the National Addiction Centre suggests that (at least in men) most co-morbid "depression is secondary to the drinking problem" and that drinking problems are a major cause of depression. ${ }^{46}$

The second limitation of our study, also related to the cross-sectional design, is the potential for reporting bias. Depressed persons would be more likely to report more stress at work (although reporting bias would probably not affect the measurement of alcohol related variables). However, as mentioned above, longitudinal studies have shown that job stress predicts depressive symptoms prospectively. ${ }^{43}{ }^{44}$ In addition, one would expect that such reporting bias would affect all work indicators similarly. In our study, however, the relation with alcohol was specific to effort-reward imbalance, with no association with job control. This suggests that reporting bias is unlikely to explain the association between psychosocial work environment and drinking.

Thirdly, we did not have data on income or occupation based measures of socioeconomic position, and these factors could confound the association between effort-reward imbalance and problem drinking. However, education has been repeatedly shown to be the best socioeconomic predictor of various health outcomes in central and eastern Europe, ${ }^{47}$ and occupation based classifications traditionally used in the region are not useful for ranking persons into a hierarchy ${ }^{47}$

Finally, representativeness of the samples should be considered. While the selected urban centres cannot be entirely representative for the whole countries, available indicators of socioeconomic characteristics, health behaviours, and mortality suggest that Novosibirsk, Krakow, and Karvina/Havirov approximate well the national data for Russia, Poland, and the Czech Republic, respectively. Response rates were similar in the three centres, and there is no indication that differences between responders and non-responders in work or drinking characteristics varied between countries. It is unlikely that non-response influenced the results.

In summary, our results are consistent with the proposition that effort-reward imbalance at work is associated with high alcohol intake and problem drinking. It remains to be clarified whether depressive symptoms mediate the effect of work characteristics on drinking or whether they are a consequence of drinking.

\section{ACKNOWLEDGEMENTS}

The study was funded by the Wellcome Trust. The sponsor played no role in the design, conduct, analysis, or interpretation of the study. $M$ Marmot is recipient of the MRC Research Professorship. The authors are grateful to Professor Robin Room for advice on the measurement of alcohol consumption and problem drinking.

\section{Authors' affiliations}

M Bobak, H Pikhart, M Marmot, International Centre for Health and Society, Department of Epidemiology and Public Health, University College London, UK

R Kubinova, Centre for Environmental health, National Institute of Public Health, Prague, Czech Republic

S Malyutina, Y Nikitin, Institute of Internal Medicine, Siberian Branch of the Russian Academy of Medical Sciences, Novosibirsk, Russia

A Pajak, R Topor-Madry, Department of Epidemiology and Population Sciences, Jagiellonian University, Krakow, Poland

H Sebakova, Regional Public Health Service, Ostrava, Czech Republic 
W Caan, Department of Public and Family Health, Anglia Polytechnic University, Chelmsford, UK

Competing interests: none

\section{REFERENCES}

1 Siegrist J, Peter R, Junge A, et al. Low status control, high effort at work and ischemic heart disease: prospective evidence from blue-collar men. Soc Sci Med 1990;31:1127-34.

2 Karasek RA, Theorell T, Schwartz JE, et al. Job characteristics in relation to the prevalence of myocardial infarction in the US Health Examination Survey (HES) and the Health and Nutrition Examination Survey (HANES). Am J Public Health 1988;78:910-18.

3 Johnson JV, Stewart W, Hall EM, et al. Long-term psychosocial work environment and cardiovascular mortality among Swedish men. Am J Public Health 1996:86:324-31.

4 Bosma H, Peter R, Siegrist J, et al. Two alternative job stress models and the risk of coronary heart disease. Am J Public Health 1998;88:68-74.

5 North FM, Syme SL, Feeney A, et al. Psychosocial work environment and sickness absence among British civil servants: the Whitehall II study. Am J Public Health 1996:86:332-40.

6 Tsutsumi A, Kayaba K, Theorell T, et al. Association between job stress and depression among Japanese employees threatened by job loss in a comparison between two complementary job-stress models. Scand J Work Environ Health 2001;27:146-53.

7 Karasek R, Baker D, Marxer F, et al. Job decision latitude, job demands, and cardiovascular disease: a prospective study of Swedish men. Am J Public Health 1981;71:694-705

8 Johnson JV, Hall EM. Job strain, work place social support, and cardiovascular disease: a cross-sectional study of a random sample of the Swedish working population. Am J Public Health 1988;78:1336-42.

9 Bosma H, Peter R, Siegrist J, et al. Two alternative job stress models and the risk of coronary heart disease. Am J Public Health 1998;88:68-74.

10 Siegrist J. Effort-reward imbalance at work. In: Perrewe P, ed. Research in occupational stress and well being. Historical and current perspectives on stress and health. London: JAI Elsevier, 2002:261-91.

11 Van Loon AJ, Tijhuis M, Surtees PG, et al. Lifestyle risk factors for cancer: the relationship with psychosocial work environment. Int J Epidemiol 2000:29:785-92.

12 Puls W, Winold H, Blank T. The influence of effort-reward imbalance in the workplace on the consumption of alcohol: a written survey carried out in metal-working companies. Sucht 1998;44:183-99.

13 Crum RM, Muntaner C, Eaton WW, et al. Occupational stress and the risk of alcohol abuse and dependence. Alcoholism: Clinical and Experimental Research 1995; 19:647-55.

14 Hemmingson T, Lundberg I. Work control, work demands, and work social support in relation to alcoholism among young men. Alcoholism: Clinical and Experimental Research 1998;22:921-7.

15 Head J, Stansfeld SA, Siegrist J. The psychosocial work environment and alcohol dependence: a prospective study. Occup Environ Med 2004;61:219-24.

16 Romelsjo A, Hasin D, Hilton $M$, et al. The relationship between stressful working conditions and high alcohol consumption and severe alcohol problems in an urban general population. Br J Addict 1992;87:1173-83.

17 Niedhammer I, Goldberg M, Leclerc A, et al. Psychosocial work environment and cardiovascular risk factors in an occupational cohort in France. $J$ Epidemiol Community Health 1998;52:93-100.

18 Caan W. Alcohol and the mind. In: Caan W, De Belleroche J, eds. Drink drugs and dependence. From science to clinical practice. London: Routledge, 2002:51-68.

19 Varvasovsky Z, Bain C, McKee M. Deaths from cirrhosis in Poland and Hungary: the impact of different alcohol policies during the 1980s. J Epidemiol Community Health 1997;51:167-71.

20 Nemtsov A. Alcohol related mortality in Russia, 1980-1990s. Moscow, 2001.

21 Bobak M, Room R, Kubinova R, et al. Contribution of alcohol consumption and drinking patterns to rates of alcohol-related problems in urban populations in Russia, Poland and the Czech Republic. A cross-sectional study. J Epidemiol Community Health 2004;58:238-42.
22 Pridemore WA. Weekend effects on binge drinking and homicide: the social connection between alcohol and violence in Russia. Addiction 2004;99:1034-41.

23 Bobak M, Hertzman C, Skodova Z, et al. Association between psychosocial factors at work and non-fatal myocardial infarction in a population based case-control study in Czech men. Epidemiology 1998;9:43-7.

24 Malinauskiene V, Theorell T, Grazuleviciene R, et al. Low job control and myocardial infarction risk in the occupational categories of Kaunas men, Lithuania. J Epidemiol Community Health 2004;58:131-5.

25 Pikhart H, Bobak M, Siegrist J, et al. Psychosocial work characteristics and self-rated health in four post-communist countries. J Epidemiol Community Health 2001:55:624-30.

26 Pikhart H, Bobak M, Pajak A, et al. Psychosocial factors at work and depression in three countries of Central and Eastern Europe. Soc Sci Med 2004;58: 1475-82.

27 Malyutina S, Bobak M, Kurilovitch S, et al. Relation between heavy and binge drinking and all-cause and cardiovascular mortality in Novosibirsk, Russia: a prospective cohort study. Lancet 2002;360:1448-54.

28 Ewing JA. Detecting alcoholism. The CAGE questionnaire. JAMA 1984;252:1905-7.

29 Room R, Bondy SJ, Ferris J. The risk of harm to oneself from drinking, Canada 1989. Addiction 1995:90:499-513.

30 Rehm J, Frick U, Bondy S. A reliability and validity analysis of an alcoholrelated harm scale for surveys. J Stud Alcohol 1999;60:203-8.

31 Ramstedt $M$. Alcohol consumption and the experience of adverse consequences: a comparison of six European countries. Contemp Drug Probl 2002;29:549-75

32 Siegrist J. Adverse health effects of high effort-low reward conditions at work. J Occup Health Psychol 1996;1:27-43.

33 Siegrist J, Starke D, Chandola T, et al. The measurement of effort-reward imbalance at work: European comparisons. Soc Sci Med 2004;58:1483-99.

34 Radloff LS. The CES-D scale: a self-report depression scale for research in the general population. Appl Psychol Measurement 1977;1:385-401.

35 Moskalewicz J, Woityniak B, Rabczenko D. Alcohol as a cause of mortality in societies undergoing rapid transition to market economy. In: Cornia GA, Paniccia R, eds. The mortality crisis in transitional economies. Oxford: Oxford University Press, 1999:81-104.

36 Britton A, McKee M. The relation between alcohol and cardiovascular disease in Eastern Europe: explaining the paradox. J Epidemiol Community Health 2000;54:328-32

37 Malyutina S, Bobak M, Kurilovitch S, et al. Trends in alcohol intake by education and marital status in an urban population in Russia between the mid 1980s and the mid 1990s. Alcohol \& Alcoholism 2004;39:64-9.

38 Bobak M. Determinants of the epidemic of coronary heart disease in the Czech Republic. PhD Thesis. London School of Hygiene and Tropical Medicine. University of London, 1996.

39 Marmot MG, Wilkinson RG. Psychosocial and material pathways in the relation between income and health: a response to Lynch et al. BMJ $2001 ; 322: 1233-6$

40 Tsutsumi A, Kayaba K, Yoshimura M, et al. Association between job characteristics and health behaviors in Japanese rural workers. Int J Behav Med 2003; 10:125-42.

41 McGauran A. Got the time? News. Public Health News, 30 July 2004.

42 Barron H. Stress. 21 st century blues. Unison Unimagazine 2004;12:12-13.

43 Stansfeld SA, Fuhrer R, Shipley M, et al. Work characteristics predict psychiatric disorder: prospective results from the Whitehall II study. Occup Environ Med 1999;15:302-7.

44 Niedhammer I, Goldberg M, Leclerc A, et al. Psychosocial factors at work and subsequent depressive symptoms in the Gazel cohort. Scand J Work Environ Health 1998;24:197-205.

45 WHO. Guide to mental and neurological health in primary care. London: Royal Society of Medicine Press, 2004

46 Edwards G, Marshall EJ, Cook CHC. The treatment of drinking problems. A guide for the helping professions. Cambridge: Cambridge University Press, 1997

47 Bobak M, Powles J. Poverty and non-communicable diseases in Central and Eastern Europe and the former Soviet Union. A report for the NonCommunicable Diseases and Mental Health Cluster, WHO Geneva. London: University College London, 2001. 